\title{
Effect of Graphene Oxide and Graphite on Dry Sliding Wear Behavior of Polyester Composites
}

\author{
MARIAN BASTIUREA ${ }^{1 *}$, DUMITRU DIMA², GABRIEL ANDREI ${ }^{1}$ \\ ${ }^{1}$ University Dunarea de J0S, Faculty of Engineering, 47 Domneasca Str., 800008, Galati, Romania \\ 2University Dunarea de J0s, Faculty of Sciences and Environment, 47 Domneasca Str., 800008, Galati, Romania
}

\begin{abstract}
Graphene oxide and graphite filled polyester composites were prepared by using conventional melt-mixing methods in order to improve tribological performance of polyester. It was investigated friction stability, microhardness, friction coefficient, and specific wear rate of the composites in details. It was found that the presence of graphite and graphene oxide influenced friction coefficient and wear rate of the composites. Graphene oxide decreased wear rate with increasing of test speed and graphite decreased wear rate for composite for all speeds. Tribological performance of the polyester/graphene composites is mainly attributed to bigger thermal conductivity for graphene, which can easily dissipate the heat which appears during the friction process at bigger forces. The positive influence of graphite on coefficient of friction (COF) of the composites is the result of the clivage of graphite layers during the loadings due to van der Waals weak bonds between the graphite layers.
\end{abstract}

Keywords: graphene oxide, graphite, polyester, wear, friction

The crystalline lamellar structure of graphite allows the basal planes to slide easily over one another without disintegrating and thus makes itan effective solid lubricant. The lubricity behaviour is ascribed to the $\mathrm{C}-\mathrm{C}$ bonding between the individual carbon atoms and to the van der Waals bonding forces between the planes and the presence of condensable vapors such as water. This super lubricity has been explained by the incommensurability between rotated graphite layers [1]. Graphite, in general, is added in friction composites to smoothen the unwanted fluctuations with operating parameters [2]. The slipperiness of graphite is not an intrinsic property. The presence of vapors, such as water, is required for graphite to lubricate in vacuum or dry environments, the friction and wear rate of graphite are high. A widely accepted explanation involves weakening of the binding force between basal planes near the surface, thereby allowing these planes to shear easily. This weakening results from proposed chemisorption or intercalation of vapor molecules near the surface, leading to an increase in the interlayer spacing between near surface basal planes [3]. As the building block of graphite, graphene also exhibited low friction both in atmospheric environment [4] and an ultra high vacuum condition [5]. Since the discovery of graphene, which is the basic layer of carbon atoms, while graphite is a superposition of graphene layers, there have been studied the mechanical, thermal and tribologic properties of graphene as well as their influence in the polymer composites. Tribologic properties of graphenes have been studied using AFM, and it has been found that they have a different behavior from that of graphite. It has also been found that friction force, which appears between graphene and tip, decreases in accordance with the increase of layers numbers, due to van der Waals forces which appear between tip and the graphene layer, thus being independent from value of the force applied to tip $[4,6]$. The friction force which appears betw een tip of the AFM and the graphene is 5 times bigger compared with the friction force which appears between graphite and the tip of AFM which are influenced by testing speed. This kind of velocity dependence has been explained by the thermally activated stick-slip effect [4].
The variation of friction with the number of layers of graphene was attributed to the effect of electron-phonon coupling [5] as well as to puckering effect [7]. It was reported that bulk graphite has higher friction than onelayer and two-layer graphene, whereas it was observed that friction on graphene approaches that of graphite as the number of layers increases. Graphene layers with more than 5 layers exhibited friction properties similar to those of bulk graphite [7]. Friction coefficient of graphenes stored on a Si substratum was measured as having the value 0.10.15 [8] or 0.02 [9]. This tendency depends on the bonds established between graphene and the support material. The stronger the bonds the faster the tendency is to disappear [10].

There has been studied the graphene influence on tribological properties of the composites formed with different polymers. For poly-ether-ether-ketone composites, the wear rate increased 3 times, while the friction coefficient has almost the same values as basic matrix. These influences are due to hardness reduction with $20-25 \%$. This lower hardness indicates that the material is more prone to plastic deformation, thereby enhancing the wear $[11,12]$. However graphene oxide improves the friction coefficient of the composite formed with PEEK or PTFE, due to chemical bonds formed with these [13-15]. The friction coefficient of epoxy, $\mathrm{Ni}_{3} \mathrm{Al}$, zirconia or tungsten carbide-graphene composite reduces indicating that the addition of graphene could form a protection layer during sliding process [16-21]. Graphene oxide in the composite formed with polyacrylonitrile reduces de friction coefficient 3 times and the wear rate 4 times, and the good tribological performance of the composite was due to the stress and thermal transfer of carbon-based components [22-24]. Graphene oxide has the same powerful influence in the composite formed with epoxy, when the wear rate is reduced with $90 \%$ while the wear coefficient increased when it is associated with the wrinkled surface morphology of $G 0[25,26]$. The influence of the graphene oxide on the wear rate of the composites formed with nylon is manifested by its reduction with $92 \%$ while the friction coefficient is decreased with $14 \%$.

\footnotetext{
* email: mail: marian_bastiurea@yahoo.com
} 
However, wear rates of nylon with graphene oxide nanocomposites slightly decrease with the increase in load. It is known that graphene, as filler with high strength and high thermal conductivity, can improve the load carrying capacity and transmission of frictional heat of the composites [27-29]. The high wear resistance of the $\mathrm{MoS}_{2}$, or zinc sulfide-reduced graphene oxide composites is mainly attributed to the enhanced toughness of the composites and the synergistic effect of the reduced graphene oxide and $\mathrm{MoS}_{2}$ or zinc sulfide [30], [31]. The same synergistic effect was suggested to be an explanation for lower friction coefficient in polyimidegraphene oxide nanocomposites [32].

Graphite also has a strong influence on tribological properties in the composite it forms with polyethylene, thus the wear rate has increased with $97 \%$, due to the existence of graphite aggregates, and the residual acid and exposed reactive groups on graphite which result in poor interfacial interaction with the matrix, leading to load transfer failure from polymer matrix to nanofiller [12]. In the composite formed with epoxy and silicon carbide wear rate was decreased with $50 \%$, by the process of transfer film on the contact surface. Addition of graphite in glass-epoxy composite exhibits lower weight loss, whose value drops as the percentage of graphite increases in the composite [33]. Under lower loads, for example, composite with medium-size graphite particles showed high coefficient of friction (COF) while under high pressure conditions (3 and $4 \mathrm{MPa}$ ) composite with large-sized graphite particles show ed highest COF. Composites with small-size graphite particles showed lowest range of COF under highest pressure-speed conditions. In general, magnitude of COF was specific to both, particle size of graphite and pressurespeed conditions. This was attributed to the fact that the mechanical interlocking of the asperities was high and the shear stress induced asperity deformation was insignificant causing the formation of underdeveloped contact patches [2]. Friction coefficient for polyester was measured as being 0.49 [34] or 0.8 [35]. To date, the friction reduction and wear resistance of graphene oxide/polyester have been rarely referred to. In this study, the tribological behaviors of the graphene oxide and graphite/ polyester composites are investigated, as we aim to develop a simple and feasible route for fabricating graphene/polyester composites. It is anticipated that these composites may find large potential applications in automotive industry, not only for their excellent thermal and mechanical properties but also for their potential friction and wear reduction.

\section{Experimental part}

Materials and methods

Graphite was purchased from $\mathrm{KOH}-\mathrm{I}-\mathrm{NOOR}$, and the medium size of the graphite particles was of 50im. Polyester resin (Norsodyne H 13271TA), was supplied by Rompolymer. Graphene oxide was obtained from graphite using Staudenmaier method. The chemical reactions used to obtain graphite oxide are shown in figure 1 and figure 2 , and the chemical reactions used for polyester with graphite or graphene oxide composites are shown in figure 3.The manufacturing process of composites took place in a normal atmosphere with humidity of $30 \%$. Concentrations of fillers from composites are $0.05,0.1 \%$ wt and $0.15 \%$ wt. There were used symbols $\mathrm{G} 0.05, \mathrm{G} 0.1, \mathrm{G} 0.15$ for polyester with graphite composites with concentrations of $0.05,0.1$, $0.15 \%$ wt graphite and GO 0.05, GO 0.1, GO 0.15 for polyester with graphene oxide composites with concentrations of $0.05,0.1 \%$ wt, $0.15 \%$ wt graphene oxide. For pure polyester it was used symbol $P$.

Graphite is one of the most common and cheapest allotropes of carbon. Graphite can be transformed to graphene by the chemical process at moderate temperatures, inoxidizing-hydrogen environment. In other words, the dissolution of graphene sheets in graphite is assessed by a wedging process. In an oxidizing acid environment, in the presence of oxygen radical, $\mathrm{C}-\mathrm{C}$ bonds breaking occurs in the same time with formation of functional groups.

In extreme conditions of oxidation, carbon dioxide is formed. This process leads to the formation of graphite network goals. These goals can be observed in a perpendicular plane to the graphitic network.

Among the functional groups of graphene oxide and hydrogen and oxygen atoms from the polyester matrix can be performed strong chemical bonds such as hydrogen bonds. Besides these links, chemical bonds van der Waals type can also be achieved, which are weaker but in a large number.

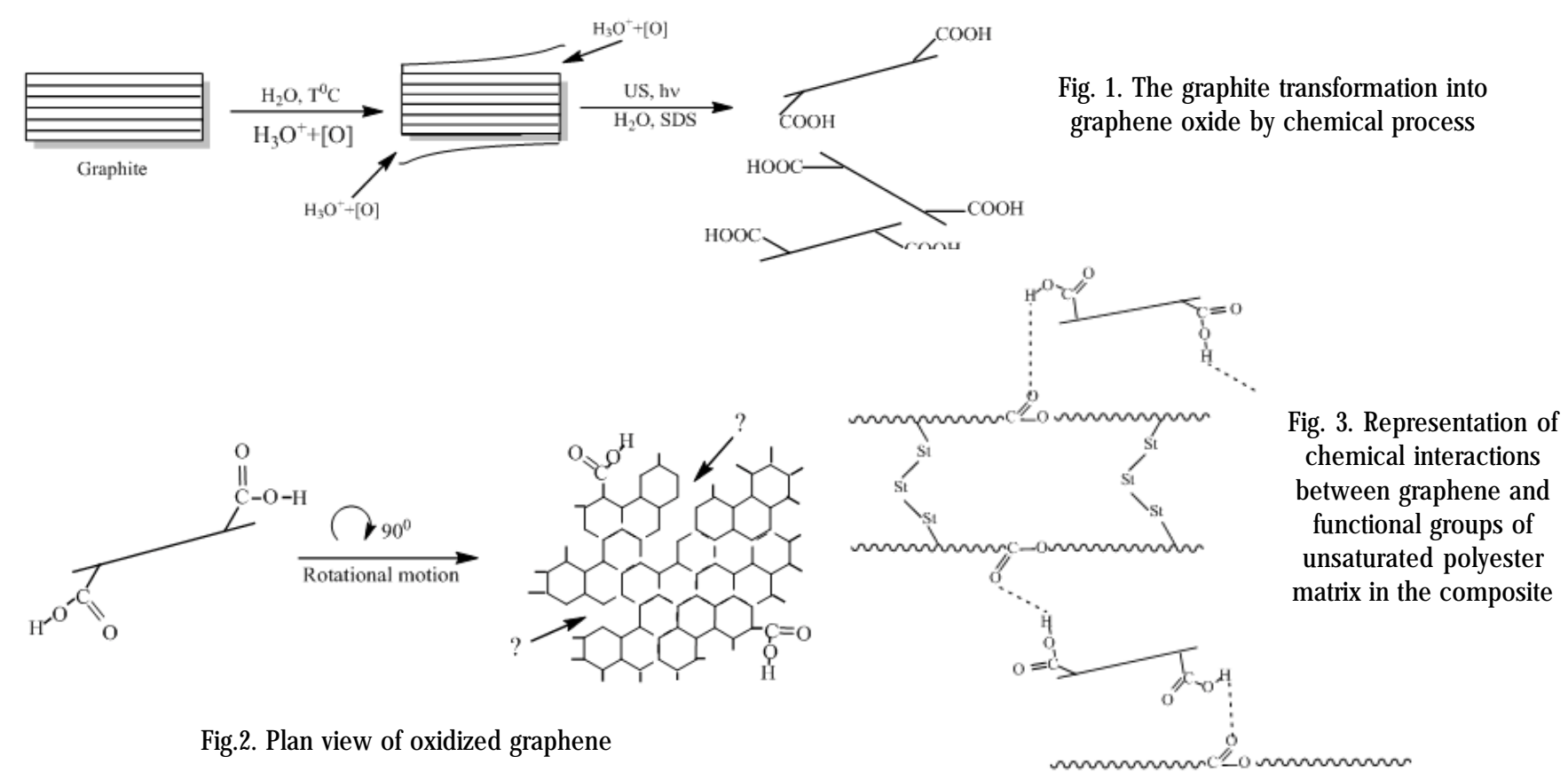


The block-on-ring test has been performed in an atmosphere with humidity of $50 \%$ at room temperature on the CEMTUMT-2 tester. Each test has been performed on 5 samples from each material, with the following dimensions $\mathrm{L} \times \mathrm{Ixh}=45 \times 8 \times 4 \mathrm{~mm}^{3}$. As counterpart ring it has been used a stainless steel ring which is outside ring of KBS 30202 bearing. For each test it has been used a ring which was cleaned with acetone before and after the test and dried in the open air. Testing speeds are $0.25,0.5,0.75 \mathrm{~m} / \mathrm{s}$, and the testing distance is $3000 \mathrm{~m}$, the loads are $5 \mathrm{~N}, 10 \mathrm{~N}$, $15 \mathrm{~N}$, which means 9 different test types for each material. Determination of the wear rate has been made by calculating mass loss, and the samples and rings have been weighed before and after testing with AB204-S/FACT scales from Mettler Toledo with accuracy of $10^{-4} \mathrm{~g}$.

\section{Results and discussions}

Wear is not a substantial property. The dependence of wear on so many variables (applied load, sliding velocity, counterface roughness, sliding media, temperature, humidity etc.) addresses the fact that there is no individual parameter that can represent wear response.

\section{Friction coefficient}

There are two main mechanisms which contribute to the friction between polymers and steel. These are adhesion and abrasive and their relative contribution depends on the load, roughness, sliding speed, humidity, as well as on the chemical, mechanical, and geometrical properties. On rough surfaces the deformation component is significant, while on smooth surfaces the adhesion becomes more important. In general, friction coefficient decreases, increases, or stabilizes, depending on the formation of thin polymer film, changing in the ploughing friction component due to changing of interface topography [36]. According to the measurements made with AFM, graphene has a bigger COF comparing with that of the graphite [4-7]. This paper studies graphite and graphene oxide influence on composites formed with polyester. The load, sliding speed, and sliding distance are the main parameters influencing the friction and weight loss. Figure 4 shows the influence of speed, force and sliding distance on COF. As can be observed in figure $4 a$, b for pure polyester and $\mathrm{G} 0.05$, COF is not significantly influenced by load force, while for GO 0.15, COF increases at the same time with increase of speed. Graphene oxide increases the COF of the GO 0.05 composites, while the graphite decreases COF in $\mathrm{G} 0.05$ composites, as it is smaller than pure polyester. Figure $4 \mathrm{c}$, d shows the COF influence on GO 0.1 and G 0.1 composites by load force. The increase of graphene oxide influence leads to decrease of COF, below that of pure polyester and it is influenced by load force. Friction COF of GO 0.1 is smaller than that of pure polyester but bigger than that of $G 0.1$. This is due to stronger cleavage of graphite bulk than in graphene oxide. Figure $4 \mathrm{e}, \mathrm{f}$ shows the decrease of COF for $\mathrm{G} 0.15$ and $\mathrm{GO} 0.15$, where the decrease is bigger for $\mathrm{G} 0.15$ as it was expected. Figure 4 a-e shows that for polyester COF is not significantly influenced by testing speed and load speed. For polyester with graphene oxide and polyester with graphite, COF decreases at the same time with increase of additives concentration, as the tendency for polyester with graphene oxide composites is to decrease below the values obtained for pure polyester.

The positive influence of graphite on COF of composites is due to cleavage of graphite layers during loading determined by van der Waals weak bonds between the graphite layers. The bigger the graphite concentration in the composite, the more cleavage points appears, which leads to COF decrease.

In diagrams shown in figure 4, graphene oxide in small concentrations has a negative influence of COF on

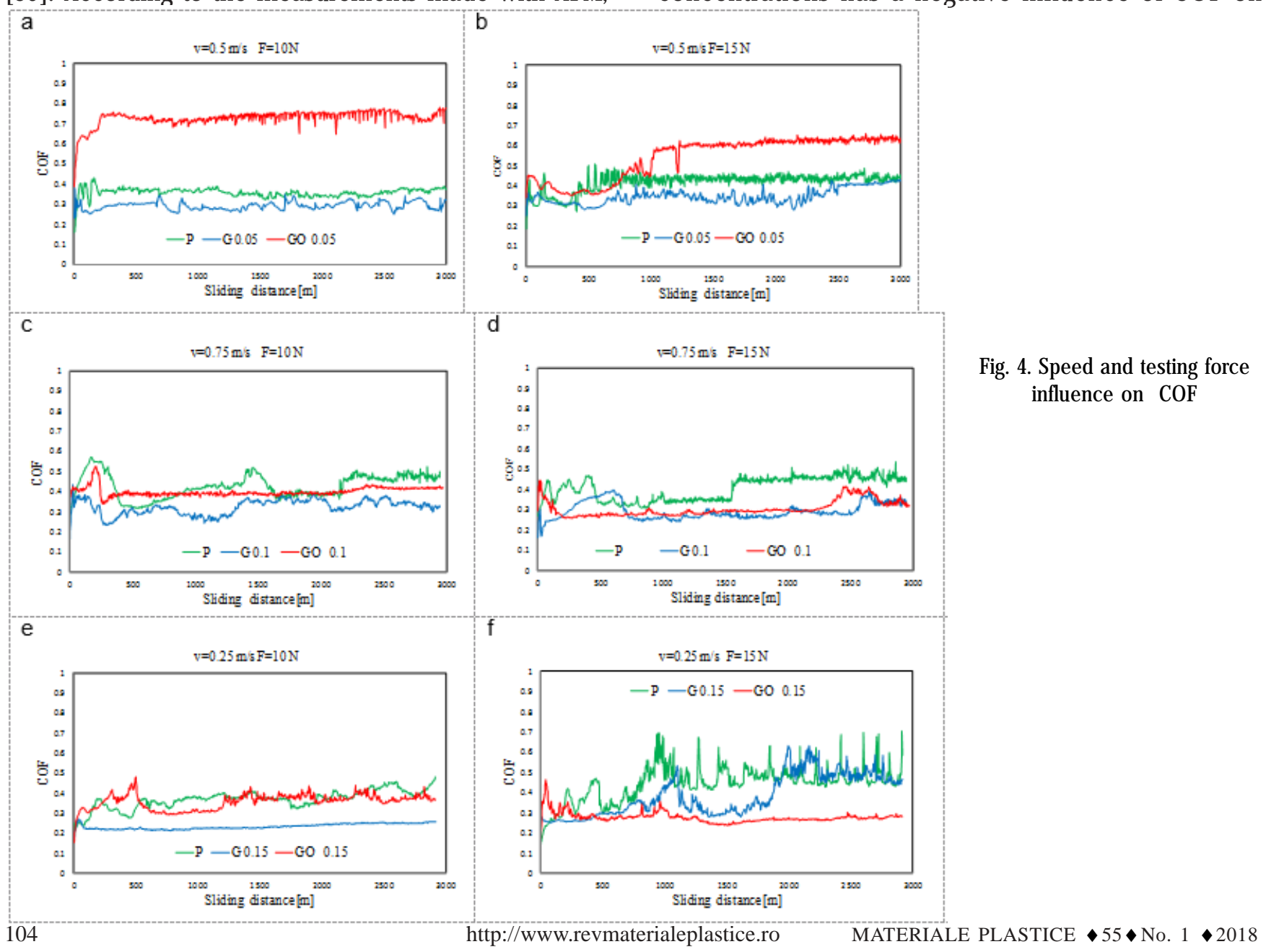




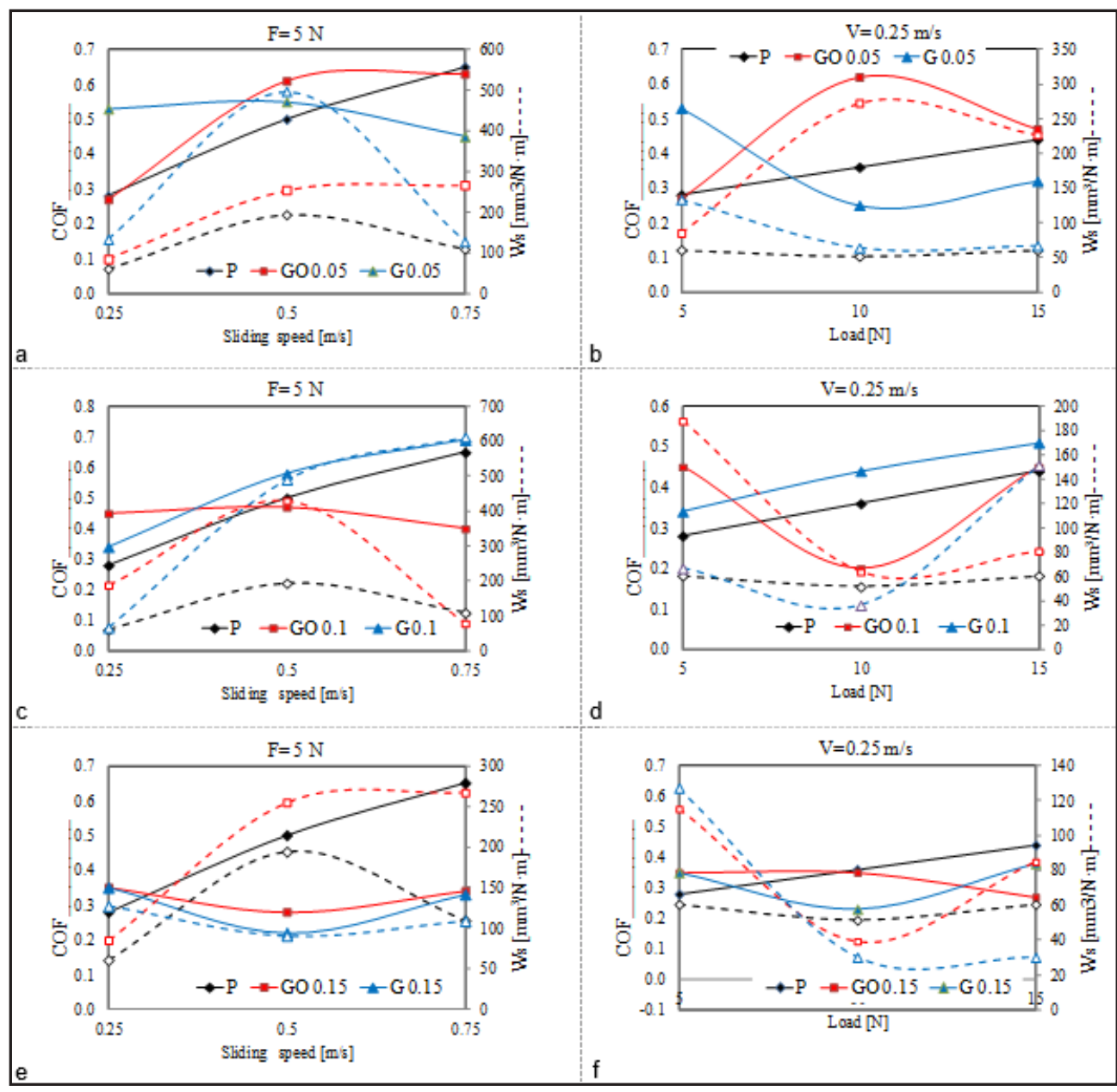

Fig. 5. COF, wear rate vs load and sliding speed

composites formed with polyester, but, at the same time while increasing the graphene oxide concentration it can be observed a decrease of COF, as for bigger load forces, $\mathrm{COF}$ is below that of pure polyester. This decrease of COF while load force increases, can be explained as the high thermal conductivity of graphene which allows fast elimination of heat from contact zone. This is also due to bigger COF of graphene comparing with that of graphite. Medium COF of polyester with graphite composites is situated in the 0.2-0.4 range, which are smaller medium values compared with those of pure polyester, which has medium values of COF in the 0.3-0.5 range.

Figure 5 a,c,e shows speed influence on the medium values of COF for load $F=5 \mathrm{~N}$. For the same load and increasing speed, graphite influence on medium COF positive, decreasing its values at the same time with increase of graphite concentration. Thus, for $\mathrm{G} 0.15$ the medium COF values are approximately $50 \%$ smaller than those of pure polyester. The same tendency is manifested with polyester with graphene oxide composites. Figure 5 $b, d$, $f$ shows medium values of COF for the testing speed $v=0.25 \mathrm{~m} / \mathrm{s}$. For the same load force it can be observed that COF decreases at the same time with the increase of graphite concentration, which is smaller than that of pure polyester for $G 0.05$ and $G 0.15$. The same tendency is manifested with graphene oxide composites, as COF decreases at the same time with the increase of graphene oxide concentration. The increase of graphene oxide concentration leads to the decrease of medium values of COF, but the medium values of COF for graphene oxide composites are bigger compared with those of polyester with graphite composites. The influence of graphite on friction of composite increased with speed increase and all polyester/graphite composites had COF 10-49\% lower than pure polyester for all tests which had sliding speed $v$
$=0.75 \mathrm{~m} / \mathrm{s}$. This is due to bigger cleavage of graphite layers compared with that of graphene oxide layers and of smaller friction coefficient of graphite compared with that of graphene oxide. Graphene oxide decreased COF only for GO 0.1, as this composite had COF 7-44\% smaller than pure polyester. The influence of graphene oxide in GO 0.05 and $\mathrm{G} 0.15$ also increased friction. This was in correlation with bigger value of COF for graphene than graphite.

\section{Specific Wear Rate}

Specific Wear Rate (the volume loss per unit sliding distance, divided by the load) is the volume from the tested material which was lost because of friction, divided by the load and the sliding velocity. The wear rate of the materials was calculated using formula 1 [37]:

$$
w_{s}=\frac{1}{F_{N} v \rho} \cdot \frac{\Delta m}{\Delta t}
$$

where:

$\mathrm{W}_{\mathrm{s}}$ - specific wear rate $\left[\mathrm{mm}^{3} / \mathrm{N} \cdot \mathrm{m}\right], \mathrm{F}_{\mathrm{N}}$ - applied normal force $[\mathrm{N}], v$ - velocity $[\mathrm{m} / \mathrm{s}], \rho$ - density $\left[\mathrm{kg} / \mathrm{mm}^{3}\right], \Delta \mathrm{m}$ mass loss [ $\mathrm{kg}], \Delta \mathrm{t}$ - time interval [s].

Figure $5 \mathrm{a}$, c, e shows that addition with graphite and graphene oxide increases the wear rate in composites formed with polyester. For $F=5 \mathrm{~N}$ it can be observed that when the speed increases the proportions between wear rate of the composites and pure polyester are kept. All composites have bigger wear rates than pure polyester, exceptfor $\mathrm{G} 0.15$ and $\mathrm{GO} 0.15$ composites, which are tested at the speed of $0.5 \mathrm{~m} / \mathrm{s}$. When analyzing the data in figure $5 \mathrm{~b}$, d,e it can be observed that if the speed is constant $(v=$ $0.25 \mathrm{~m} / \mathrm{s}$ ) and the value of the load force increases, Ws values decrease for the value $\mathrm{F}=10 \mathrm{~N}$, and the value $\mathrm{F}=$ $15 \mathrm{~N}$ increases but below the values obtained for $\mathrm{F}=5 \mathrm{~N}$. 


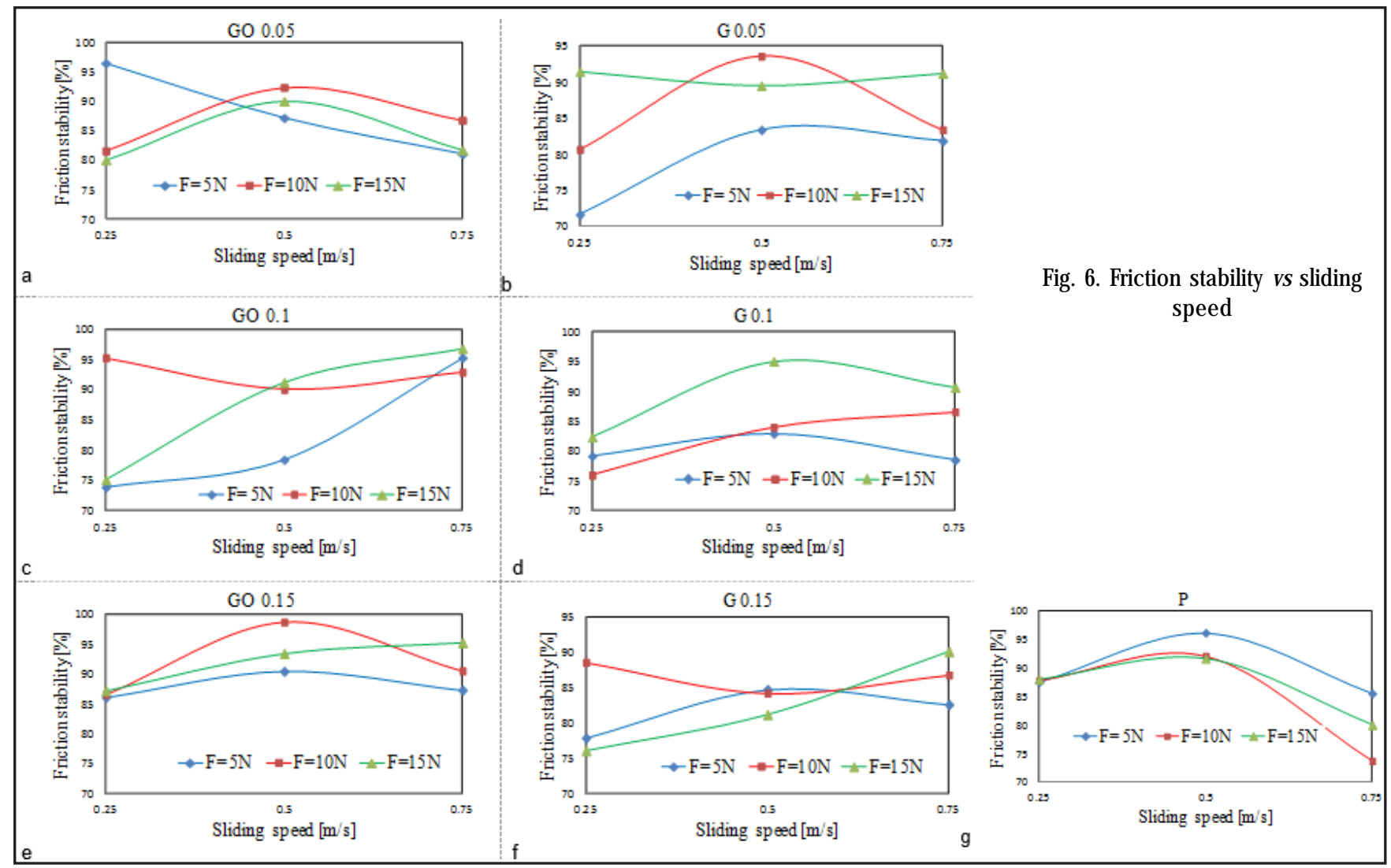

It can be concluded that for small load forces the biggest values of Ws can be obtained. Graphite decreased wear rate for composite for all speeds. During the test with $\mathrm{v}=$ $0.75 \mathrm{~m} / \mathrm{s}$, composites with graphite had a $44-90 \%$ smaller wear rate than pure polyester, which was the result of cleavage between graphite layers. Graphene oxide decreased wear rate with increasing of speed and, for $v=$ 0.75 wear rate of composite was $13-93 \%$ smaller than pure polyester.

\section{Friction stability}

The friction behavior was further analyzed in terms of percentage friction stability against the applied speed in figure 6 . Friction stability was calculated with formula 2:

$$
F_{s}=\frac{\mu_{\operatorname{med}}}{\mu_{\max }} \times 100
$$

The higher the stability range the better the performance rating of a material under the set of selected operating parameters is. If such curve is flat and does not show undulations, the friction material is rated as having minimum sensitivity towards load or speed. The sharper the slope, the poorer the rating of performance is. The unstable nature of friction layers is reported to be influenced by mechano-chemical and surface energy interactions, which vary with the nature of the composition due to the difference in particle size of nanofiller. The formation of the operating friction film at the interface between composite and ring has been reported to follow fundamentally two different mechanistic pathways. The first path involves the transfer of material to the interface at high temperatures which subsequently disintegrates into micron sized third body debris. The second pathway involves the formation of two layer bodies, i.e., independently both at the ring and at the composite surface where the compositional difference between the two forms the driving potential to friction stabilization [2]. Medium and maximum values of COF are measured in the wear area steady state, where the wear regime is stabilized. As seen in figure 7, the stability range of composite was P (74-96\%), GO $0.05(80-96 \%)$, GO 0.1 (73-97\%), GO 0.15 (86-99\%), G 0.05 (71-94\%), G 0.1 (75$95 \%), G 0.15$ (76-90\%). With increase in severity of parameters friction stability was drastically reduced and its deviation as a function of pressure increased. The extent, however, was composition specific. The best behavior from these points of view was exhibited by GO 0.15 and the friction stability decreases in following order: $G 0.15, G 0$ 0.05 , G 0.1, P, G 0.05 and GO 0.1. The GO 0.15 range of stability variation (86-99\%) was lowest and the slope was minimal. This could be results of bond between graphene oxide and polyester which results in thinnest film transfer on ring, as seen in figure $8 \mathrm{a}$.

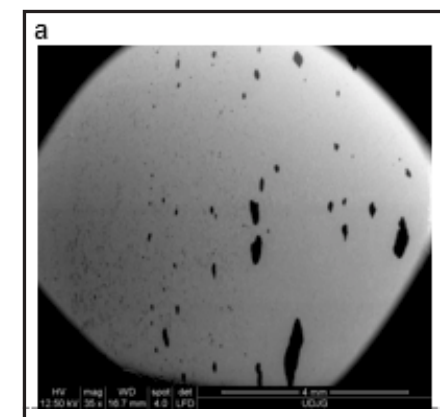

106
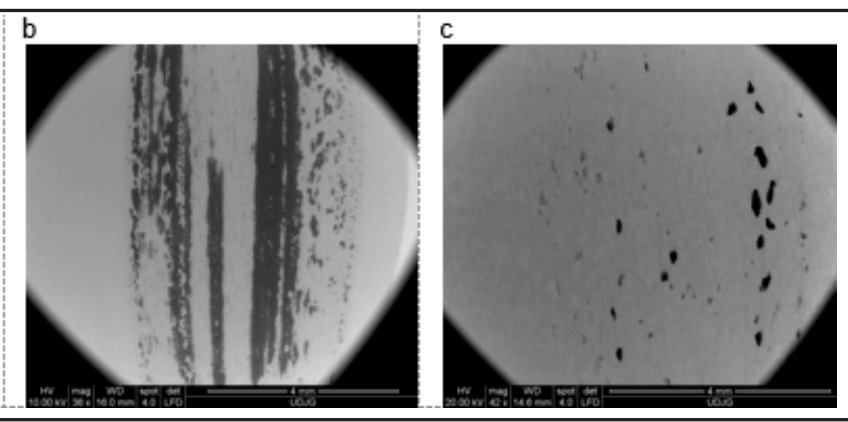

http://www.revmaterialeplastice.ro
Fig. 7. Film transfer for a) $\mathrm{GO}$ 0.15 ; b) $P$; c) $G 0.15$ for $v=0.75$ $\mathrm{m} / \mathrm{s}$ and $\mathrm{F}=15 \mathrm{~N}$ 


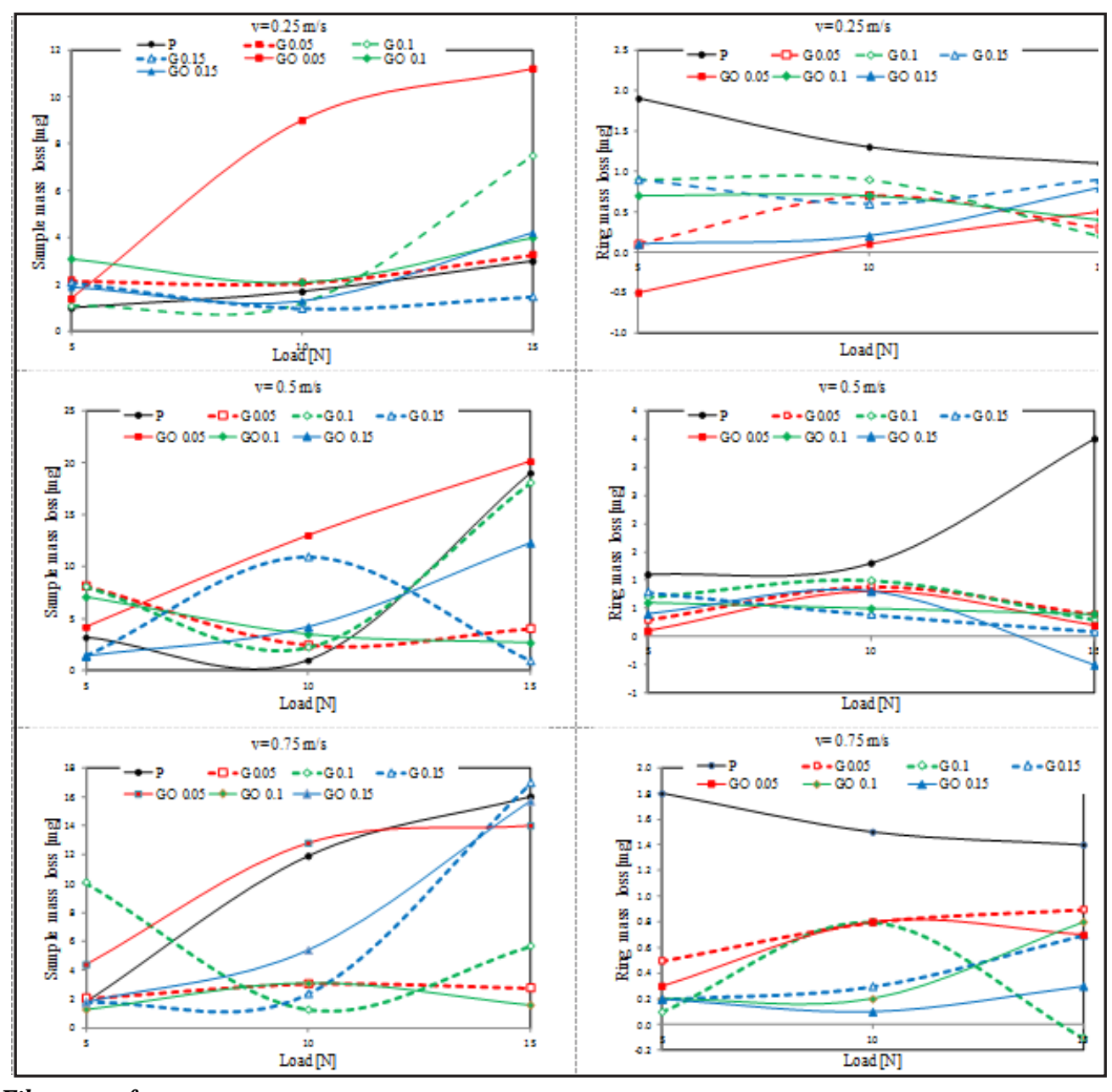

Fig. 8. Mass loss vs sliding speed or load for sample and ring (counterface)

\section{Film transfer}

When a polyester composite slides over a counterface steel ring, without lubricants, if the adhesive bonds formed between composite and steel ring become stronger than the cohesive bond of the composite, some parts of the composites are transferred onto the steel ring forming a transfer film, another part of the composites is removed, forming wear debris. The transfer film can change the contact conditions between the counterpart and the surface, thus influencing the wear response and the magnitude of the wear rate [19, 38-55].

Composites transfer occurs sequentially and layers are formed by an agglomeration of wear particles both composites and steel. The layer increases in length and width as function of sliding distance. The transfer film may be in the form of rugged block adhering to the metallic surface. There are few factors that determine the transfer of the composites: the deformation of surface asperities of composite under load, the adherence of composite to counterface and the fracture of composite in the substrate. The first stage of composites wear is abrasion, which involves eliminating superficial roughness due to technological process, also known as running in. After eliminating the roughness, the transfer film reaches its maximum dimensions, the steady state wear type is installed. Transfer film formation is influenced by bonds formed between the composite and the counterface. The stronger the bonds, the smaller the wear is. As shown in figure 4 all materials have the same running in period, as graphite and graphene reduced this area in the composites they form with polyester.

As figure 7 shows, the transfer film formed by pure polyester on the counterface is bigger than those formed by polyester/graphite and polyester/graphene oxide composites. This is due to the fact that wear debris of the composites acts as a third body. The two-body abrasion takes place when hard counterface asperities plow and cause plastic deformation or fracture of the softer material (in our case, polyester); while the three-body abrasion occurs when hard abrasive particles or wear debris are introduced into the sliding contact either as products of two-body abrasion [56]. Further, it was found that the released particles of graphene oxide/ polyester and graphite/polyester composite as wear debris during sliding of contact surface at high rotation speed act as three body roller bearings so they reduce film transfer on counterface and COF. The third body is not uniform in the running in wear area, where the biggest COF is usually recorded and the wear rate is bigger. After the wear debris accumulates and the third body is formed, COF stabilizes its oscillations around the medium value being smaller and wear rate being smaller, too.

If the interfacial bonding is stronger than cohesive of the weaker material, then this material is fractured and the polymer transfer takes place, otherwise fracture occurs at the interface. As a rule, in polymers the surface forces and forces acting between polymer chains are nearly equal and fracture often occurs in the bulk of polymers. This is not always the case. It was observed for metal-polymer contact that metal is transferred to the polymer surface under certain conditions [57].

Table 1 also shows COF, ring mass loss and sample mass loss. The additives influence on COF has been shown previously where the graphite slightly reduces COF and graphene oxide increases COF. The influence of those on sample mass loss is negligible, while ring mass loss is strongly influenced by their presence. If we study the mass loss values for counterface it can be observed that the fillers have a significant influence on the abrasive behavior of the polyester sample on counterface, which decreases 
Table 1

FRICTION PARAMETERS FOR $v=0.75 \mathrm{~m} / \mathrm{s}, \mathrm{F}=15 \mathrm{~N}$

\begin{tabular}{|l|c|c|c|}
\hline Sample & COF & $\begin{array}{c}\text { ring mass } \\
\text { loss }\end{array}$ & $\begin{array}{c}\text { sample } \\
\text { mass loss }\end{array}$ \\
\cline { 3 - 4 } & & {$[\mathrm{mg}]$} & {$[\mathrm{mg}]$} \\
\hline $\mathrm{P}$ & 0.40 & 1.4 & 16.0 \\
\hline G 0.15 & 0.36 & 0.7 & 17.0 \\
\hline GO 0.15 & 0.59 & 0.3 & 15.7 \\
\hline
\end{tabular}

a few times. This abrasive behavior, which is much smaller for composites compared with the pure polyester, demonstrates that the additives used do not only influence the friction coefficient of the material but also its durity. Analyzing tests results it can be observed that the adhesion to counterface is strongly influenced by the presence of the additives. Graphene oxide and graphite, besides the lubrication effect, also decrease the counterface wear and form the third body which has the role of roller bearing. Due to easily forming the third body in the polyester/ graphiteand polyester/graphene oxide composites, as well as the roller bearing behavior, the counterface wear is a few times smaller comparing with the counterface wear when pure polyester is tested, (fig. 8).

Figure 9 a, b shows a smooth surface on graphene oxide flake on the surface between composite and counterface. Figure $9 c$, d shows w rinkled graphite flakes on the contact surface between composite and counterface.
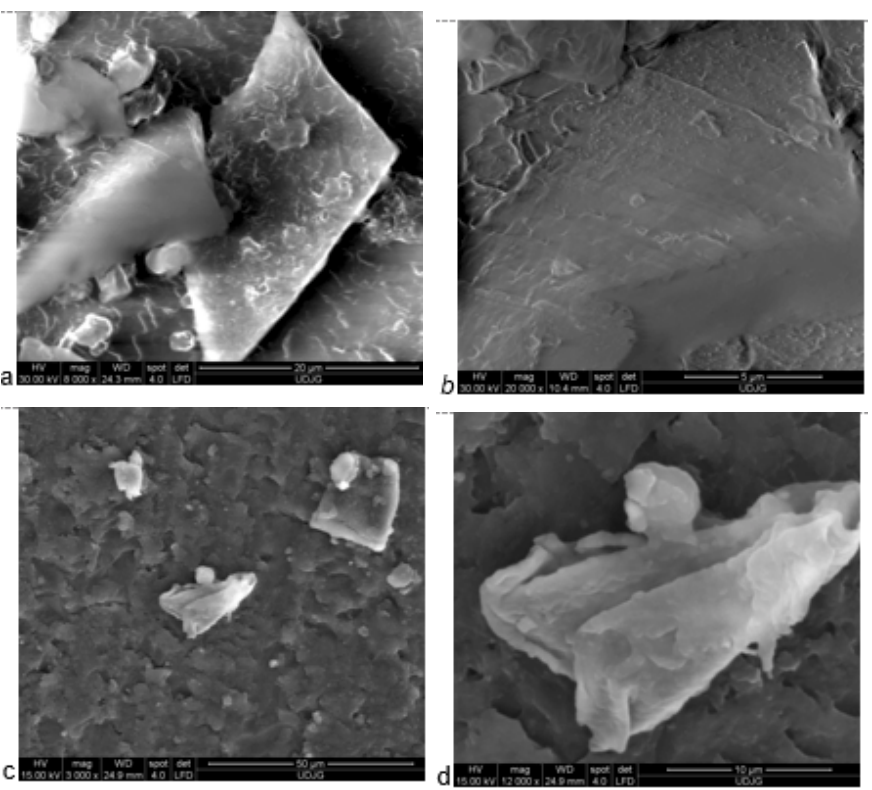

Fig. 9. SEM images for GO 0.15 a) magnitude $8000 x$; b) magnitude 20000x; $G 0.15$ c) magnitude $3000 x$; d) magnitude $12000 x$, tested at $F$ $=15 \mathrm{~N}, \mathrm{v}=0.75 \mathrm{~m} / \mathrm{s}$.

\section{Microhardness Vickers}

The mechanical performance of the products was evaluated with the Vickers microhardness test. The average values of at least five points of the randomly selected regions in each sample are reported. The influence of graphite and graphene oxide concentration on the microhardness (Vickers scale) behavior in composites is given in figure 10. The change in hardness is given as a function of fillers concentration. Each sample is subjected to 40 indentations where the distance between the indents has been kept $>4 d$, where ' $d$ ' is the diagonal of the indentation, in order to avoid overlapping of any possible crack propagation.
Microhardness Vickers has been determined by using the equation 3:

$$
\mu H V=\frac{F}{S}=\frac{0,1891 \times F}{d^{2}}
$$

where:

$\mathrm{vHV}$ - microhardness Vickers [ $\left.\mathrm{N} / \mathrm{mm}^{2}\right]$, F - applied load $[\mathrm{N}], \mathrm{S}$ - the surface area of the resulting indentation $\left[\mathrm{mm}^{2}\right]$, $d$ - diagonal of the indentation left in the surface of the material after removal of the load [mm];

Tests have been made on PMT-3 tester, value of applied force of identer being $0,2 \mathrm{~N}$.

From the tests made on graphene and graphite resulted big differences between the microhardness Vickers and the two materials, while graphene's hardness is 10 times bigger than graphite [58]. Graphene hardness decreases in accordance with the number of layers from $0,95 \mathrm{TPa}$ for a layer to 0,27 TPa for two layers, having the hardness of 0,1 TPa for graphenes with more than four layers [59]. The influence of different allotrope of carbon on hardness of composites was studied using Vickers method thus, carbon nanotubes decrease the hardness of composites formed with epoxy [60,61], as graphite contributes to increasing hardness in composites they form [62], while graphen oxide increases microhardness of composites [27,63-68].

The hardness of composites influences both composite wear rate and wear of parts the composite is in contact with.

Figure 10 shows the additives influence on the hardness of composites formed with polyester. As can be seen, hardness of composites with graphene oxide is bigger compared with hardness of composites formed by graphite with polyester as well as hardness of pure polyester. These values are in accordance with the fact that graphene has a bigger hardness than graphite. Cleavage of graphite layers influence hardness of composites they form with polyester as well. Wear rate is inversely proportional to hardness, which is also show $n$ by bigger wear rate of graphene oxide composites in comparison with polyester and composites formed by polyester with graphite.

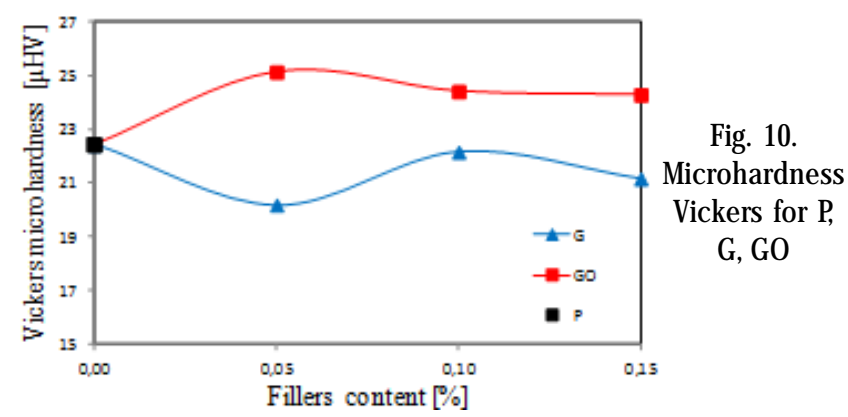

Thus itcan be concluded that materials with the biggest hardness also have the biggest COF values. Wear rate is influenced by hardness of composites and thus materials have the biggest hardness and the smallest wear rate.

\section{Conclusions}

The influence of graphene oxide and graphite on tribological behavior of polyester matrix composites has been studied using block-on-ring test. Graphite has a better influence than graphene oxide in friction of composites. All polyester/graphite composites had COF 10-49\% lower than pure polyester for all tests which had sliding speed $\mathrm{v}$ $=0.75 \mathrm{~m} / \mathrm{s}$. The positive influence of graphite on COF of the composites is the result of the clivage of graphite layers during the loadings due to van der Waals weak bonds between the graphite layers. The bigger the graphite 
concentration in composites, the more clivage points appear, which leads to COF decrease. Graphene oxide in small concentrations has a negative influence of COF in composites formed with polyester, but if the graphene oxide concentration is increased, COF decreases. Graphene oxide decreased COF only for GO 0.1, this composite had COF $7-44 \%$ smaller than pure polyester. For bigger load forces COF is below that of pure polyester. This is due to bigger thermal conductivity of graphene which can easily dissipate the heat which appears during the friction process at bigger forces. Graphite decreased wear rate for composites for all speed. During the test with $v=0.75 \mathrm{~m} /$ s, composites with graphite had a $44-90 \%$ smaller wear rate than pure polyester, which was the result of cleavage between graphite layers. Graphene oxide decreased wear rate with increasing of speed, and for $v=0.75$ wear rate of composite was $13-93 \%$ smaller than pure polyester. The best friction stability has GO 0.15 (86-99\%), followed by G $0.15(76-90 \%)$, which is due to the stronger chemical bonds between the graphene oxide and polyester, as besides the van der Waals bonds, there are also hydrogen bonds between carbonyl and carboxyl groups from the graphene oxide and ester groups from the polyester matrix. The transfer film formed by pure polyester on the counterface is bigger than those formed by polyester/graphite and polyester/graphene oxide composites. This is due to the fact that wear debris of the composites acts as a third body roller bearings. This is due to strong adhesion of polyester on the ring surface compared with composites. Microhardness of composites with graphene oxide is bigger compared with hardness of composites formed by graphite with polyester as well as hardness of pure polyester.

\section{References}

1. DIENWIEBEL M, VERHOEVEN GS, PRADEEP N, FRENKEN JWM, HEIMBERG JA. ZANDBERGEN, H.W., Superlubricity of Graphite. Phys Rev Lett 2004;92:126101. doi:10.1103/PhysRevLett.92.126101.

2. KOLLURI D, GHOSH AK, BIJWE J. Analysis of load-speed sensitivity of friction composites based on various synthetic graphites. Wear 2009;266:266-74. doi:10.1016/j.wear.2008.06.023.

3. YEN BK, SCHWICKERT BE, TONEY MF. Origin of low-friction behavior in graphite investigated by surface $x$-ray diffraction. Appl Phys Lett 2004;84:4702-4. doi:10.1063/1.1760597.

4. LEE H, LEE N, SEO Y, EOM J , LEE S. Comparison of frictional forces on graphene and graphite. Nanotechnology 2009;20:325701. doi:10.1088/0957-4484/20/32/325701.

5. FILLETER T, MCCHESNEY JL, BOSTWICK A, ROTENBERG E, EMTSEV $K$ V. SEYLLER T, et al. Friction and dissipation in epitaxial graphene films. Phys Rev Lett 2009;102.

6. LEE C, WEI X, LI Q, CARPICK R, KYSAR JW, HONE J. Elastic and frictional properties of graphene. Phys Status Solidi 2009;246:2562-7. doi:10.1002/pssb.200982329.

7. LEE C, LI Q, KALB W, LIU X-Z, BERGER H, CARPICK RW, et al. Frictional characteristics of atomically thin sheets. Science 2010;328:7680.

8. LIN L-Y, KIM D-E, KIM W-K, JUN S-C. Friction and wear characteristics of multi-layer graphene films investigated by atomic force microscopy. Surf Coatings Technol 2011;205:4864-9. doi:10.1016/j.surfcoat.2011. 04.092.

9. MARCHETTO D, HELD C, HAUSEN F, WAHLISCH F, DIENWIEBEL M, BENNEWITZ R. Friction and wear on single-layer epitaxial graphene in multi-asperity contacts. Tribol Lett2012;48:77-82. doi:10.1007/s11249012-9945-4.

10. LI Q, LEE C, CARPICK RW, HONE J. Substrate effect on thicknessdependent friction on graphene. Phys Status Solidi Basic Res 2010;247:2909-14.

11. KALIN M, ZALAZNIK M, NOVAK S. Wear and friction behaviour of poly-ether-ether-ketone (PEEK) fi lled with graphene, WS 2 and CNT nanoparticles. Wear 2015:1-8. doi:10.1016/j.wear.2014.12.036.
12. LIU T, LI B, LIVELY B, EYLER A, ZHONG WH. Enhanced wear resistance of high-density polyethylene composites reinforced by organosilane-graphitic nanoplatelets. Wear 2014;309:43-51. doi:10.1016/ j.wear.2013.10.013.

13. SONG HJ , LI N, LI Y, MIN C, WANG Z. Preparation and tribological properties of graphene/poly(ether ether ketone) nanocomposites. J Mater Sci 2012;47:6436-43. doi:10.1007/s10853-012-6574-0.

14. YANG M, YUAN J, GUO F, WANG K, ZHANG Z, MEN X, et al. A biomimetic approach to improving tribological properties of hybrid PTFE/Nomex fabric/phenolic composites. Eur Polym J 2016;78:16372. doi:10.1016/j.eurpolymj.2016.03.013.

15. DELEANU, L., BIRSAN, IG., ANDREI, G., PTFE composites and water lubrication - Tribogical characterisation. Mat. Plast., 44, 2007, p. 66

16. ZHAI W, SHI X, WANG M, XU Z, YAO J, SONG S, et al. Grain refinement: A mechanism for graphene nanoplatelets to reduce friction and wear of $\mathrm{Ni}_{3} \mathrm{Al}$ matrix self-lubricating composites. Wear 2014;310:33-40. doi:10.1016/j.wear.2013.12.014.

17. LI H, XIE Y, LI K, HUANG L, HUANG S, ZHAO B, et al. Microstructure and wear behavior of graphene nanosheets-reinforced zirconia coating. Ceram Int 2014;40:12821-9. doi:10.1016/j.ceramint.2014.04.136. 18. SUN J, ZHAO J, CHEN M, ZHOU Y, NI X, LI Z, et al. Multilayer graphene reinforced functionally graded tungsten carbide nanocomposites. Mater Des 2017;134:171-80. doi:10.1016/j.matdes. 2017.08.041.

19. LI P, ZHENG Y, SHI T, WANG Y, LI M, CHEN C, et al. A solvent-free graphene oxide nanoribbon colloid as filler phase for epoxy-matrix composites with enhanced mechanical, thermal and tribological performance. Carbon N Y 2016;96:40-8. doi:10.1016/j.carbon. 2015.09.035

20.CIRCIUMARU, A., ANDREI, G., BIRSAN, I., SEMENESCU, A., Electrical Conductivity of Fabric Based Filled Epoxy Composites. Mat. Plast., 46, 2009, p. 211

21. DIMA D, ANDREI G. Investigation of the Effect of Fe304 Particles on the Interface of Gf Pr Fa Magnetic Composites. Materwiss Werksttech 2003;34:349-53. doi:10.1002/mawe.200390073.

22. MO Y, YANG M, LU Z, HUANG F. Preparation and tribological performance of chemically-modified reduced graphene oxide/ polyacrylonitrile composites. Compos Part A Appl Sci Manuf 2013;54:153-8. doi:10.1016/j.compositesa.2013.07.014.

23. CIUPAGEA L, ANDREI G, DIMA D, MURARESCU M. SPECIFIC HEAT ANDTHERMAL EXPANSION OF POLYESTER COMPOSITES CONTAINING SINGLEWALL-, MULTIWALL-AND FUNCTIONALIZED CARBON NANOTUBES. DigJ Nanomater Biostructures 2013;8:1611-9.

24. DIMA D, MURARESCU M, ANDREI G. DISPERSION OF CARBON NANOTUBES COATED WITH IRON (III) OXIDE INTO POLYMER COMPOSITE UNDER OSCILLATING MAGNETIC FIELD. DigJ Nanomater Biostructures 2010;5:1009-14.

25. SHEN XJ, PEI XQ, FU SY, FRIEDRICH K. Significantly modified tribological performance of epoxy nanocomposites at very low graphene oxide content. Polym (United Kingdom) 2013;54:1234-42. doi:10.1016/j.polymer.2012.12.064.

26. SHEN XJ, PEI XQ, LIU Y, FU SY. Tribological performance of carbon nanotube-graphene oxide hybrid/epoxy composites. Compos Part B Eng 2014;57:120-5. doi:10.1016/j.compositesb.2013.09.050.

27. PAN B, ZHANG S, LI W, ZHAO J, LIU J, ZHANG Y, et al. Tribological and mechanical investigation of $M C$ nylon reinforced by modified graphene oxide. Wear 2012;294-295:395-401. doi:10.1016/j.wear. 2012.07.032.

28. LI Y, WANG S, WANG Q. Enhancement of tribological properties of polymer composites reinforced by functionalized graphene. Compos Part B Eng 2017;120:83-91. doi:10.1016/j.compositesb.2017.03.063.

29. LI C, XIANG M, YE L. Intercalation structure and highly enhancing tribological performance of monomer casting nylon-6/graphene nanocomposites. Compos PartA Appl Sci Manuf 2017;95:274-85. doi:10.1016/ j.compositesa.2017.01.013.

30. CHEN Z, YAN H, LIU T, NIU S. Nanosheets of $\mathrm{MOS}_{2}$ and reduced graphene oxide as hybrid fillers improved the mechanical and tribological properties of bismaleimide composites. Compos Sci Technol 2016;125:47-54. doi:10.1016/j.compscitech.2016.01.020. 
31. ZHANG S, YANG J , CHEN B, GUO S, LI J, LI C. One-step hydrothermal synthesis of reduced graphene oxide/zinc sulfide hybrids for enhanced tribological properties of epoxy coatings. Surf Coatings Technol 2017;326:87-95. doi:10.1016/j.surfcoat.2017.07.052.

32. MIN C, LIU D, SHEN C, ZHANG Q, SONG H, LI S, et al. Unique synergistic effects of graphene oxide and carbon nanotube hybrids on the tribological properties of polyimide nanocomposites. Tribol Int 2018;117:217-24. doi:10.1016/j.triboint.2017.09.006.

33. BASAVARAJAPPA S, ELLANGOVAN S. Drysliding wear characteristics of glass-epoxy composite filled with silicon carbide and graphite particles. Wear 2012;296:491-6. doi:10.1016/j.wear.2012.08.001.

34. SIERROS KA, KUKUREKA SN. Tribological investigation of thin polyester substrates for displays. Wear 2007;263:992-9. doi:10.1016/ j.wear.2007.01.073.

35. HASHMI SAR, DWIVEDI UK, CHAND N. Graphite modified cotton fibre reinforced polyester composites under sliding wear conditions. Wear 2007;262:1426-32. doi:10.1016/j.wear.2007.01.014.

36. ZSIDAI L, DE BAETS P, SAMYN P, KALACSKA G, VAN PETEGHEM A., VAN PARYSF. The tribological behaviour of engineering plastics during sliding friction investigated with small-scale specimens. Wear 2002;253:673-88. doi:10.1016/S0043-1648(02)00149-7.

37. ASTM. G137 -Standard Test Method for Ranking Resistance of Materials to Sliding Wear Using 2003:1-11. doi:10.1520/G0077-05R10.2. 38. LANCASTER JK. Abrasive wear of polymers. Wear 1969;14:223-39. doi:http://dx.doi.org/10.1016/0043-1648(69)90047-7.

39. ZHAO G, HUSSAINOVA I, ANTONOV M, WANG Q, WANG T, YUNG D. Effect of temperature on sliding and erosive wear of fi ber reinforced polyimide hybrids. Tribiology Int 2015;82:525-33. doi:10.1016/ j.triboint.2014.01.019.

40. SURESHA B, SHIVA K, SEETHARAMU S, KUMARAN PS. Friction and dry sliding wear behavior of carbon and glass fabric reinforced vinyl ester composites. Tribiology Int 2010;43:602-9. doi:10.1016/ j.triboint.2009.09.009.

41. BIAN D, ARADHYULA TV, GUO Y, ZHAO Y. Improving tribological performance of chemically bonded phosphate ceramic coatings reinforced by graphene nano-platelets. Ceram Int 2017;43:12466-71. doi:10.1016/j.ceramint.2017.06.116.

42. LIU D, ZHAO W, LIU S, CEN Q, XUE Q. Comparative tribological and corrosion resistance properties of epoxy composite coatings reinforced with functionalized fullerene $\mathrm{C} 60$ and graphene. Surf Coatings Technol 2016;286:354-64. doi:10.1016/j.surfcoat.2015.12.056. 43. SEDLAK R, KOVALĖÍKOVÁ A, BALKO J, RUTKOWSKI P, DUBIEL A, ZIENTARA D, et al. Effect of graphene platelets on tribological properties of boron carbide ceramic composites. Int J Refract Met Hard Mater 2017;65:57-63. doi:10.1016/j.jirmhm.2016.11.015.

44. WANG H, XIE G, ZHU Z, YING Z, ZENG Y. Enhanced tribological performance of the multi-layer graphene filled poly ( vinyl chloride ) composites. Compos Part a 2014;67:268-73. doi:10.1016/ j.compositesa.2014.09.011.

45. LIU C, YAN H, LV Q, LI S, NIU S. Enhanced tribological properties of aligned reduced graphene oxide-Fe304@polyphosphazene/ bismaleimides composites. Carbon N Y 2016;102:145-53. doi:10.1016/ j.carbon.2016.02.021.

46. KIM C, KIM S, PARK J, SONG J. Fabrication and Evaluation of Mechanical Properties of CF/GNP Composites. Procedia Manuf 2015;2:368-73. doi:10.1016/j.promfg.2015.07.065.

47. SONG H, WANG Z, YANG J, JIA X, ZHANG Z. Facile synthesis of copper/polydopamine functionalized graphene oxide nanocomposites with enhanced tribological performance. Chem Eng J 2017;324:51-62. doi:10.1016/j.cej.2017.05.016.

48. ZHAI W, SHI X, XU Z, ZHANG Q. Formation of friction layer of $\mathrm{Ni}_{3} \mathrm{Al}$ matrix composites with micro- and nano-structure during sliding friction under different loads. Mater Chem Phys 2014;147:850-9. doi:10.1016/j.matchemphys.2014.06.030.

49. GUTIERREZ-MORA F, CANO-CRESPO R, RINCON A, MORENO R, DOMINGUEZ-RODRIGUEZ A. Friction and wear behavior of aluminabased graphene and CNFs composites. J Eur Ceram Soc 2017;37:380512. doi:10.1016/j.jeurceramsoc.2017.02.024.

50. WANG J, CHENG Y, ZHANG Y, YIN Z, HU X, YUAN Q. Friction and wear behavior of microwave sintered Al $203 / \mathrm{TiC} / \mathrm{GPLs}$ ceramic sliding against bearing steel and their cutting performance in dry turning of hardened steel. Ceram Int 2017;43:14827-35. doi:10.1016/ j.ceramint.2017.07.231.

51.BHOWMICK S, BANERJ I A, ALPASAT. Friction reduction mechanisms in multilayer graphene sliding against hydrogenated diamond-like carbon. Carbon N Y 2016;109:795-804. doi:10.1016/j.carbon.2016.08.036. 52. MIRANZO P, BELMONTE M, OSENDI MI. From bulk to cellular structures: A review on ceramic/graphene filler composites. J Eur Ceram Soc 2017;37:3649-72. doi:10.1016/j.jeurceramsoc.2017.03.016.

53.GUPTA B, KUMAR N,TITOVICH KA, IVANOVICH KV, VYACHESLAVOVICH SA, Dash S. Lubrication properties of chemically aged reduced graphene-oxide additives. Surfaces and Interfaces 2017;7:6-13. doi:10.1016/j.surfin.2017.02.005.

54. WANG $Q$, WANG $H$, WANG Y, YAN $F$. The influences of several carbon additions on the fretting wear behaviors of UHMWPE composites. Tribol Int 2016;93:390-8. doi:10.1016/j.triboint.2015.09.033. 55. XIA S, LIU Y, PEI F, ZHANG L, GAO Q, ZOU W, et al. Identical steady tribological performance of graphene-oxide-strengthened polyurethane/epoxy interpenetrating polymer networks derived from graphene nanosheet. Polymer (Guildf) 2015;64:62-8. doi:10.1016/ j.polymer.2015.03.036.

56. ALBDIRY MT, YOUSIF BF. Morphological structures and tribological performance of unsaturated polyester based untreated/silane-treated halloysite nanotubes. Mater Des 2013;48:68-76. doi:10.1016/ j.matdes.2012.08.035.

57. BUCKLEY, D. H. Surface effects in adhesion, friction, wear and lubrication. Amsterdam: Elsevier; 1981.

58. RANJBARTOREH AR, WANG B, SHEN X, WANG G. Advanced mechanical properties of graphene paper. J Appl Phys 2011;109:1-6. doi:10.1063/1.3528213.

59. ZHANG Y, PAN C. Measurements of mechanical properties and number of layers of graphene from nano-indentation. Diam Relat Mater 2012;24:1-5. doi:10.1016/j.diamond.2012.01.033.

60. GOHARDANI O, WILLIAMSON DM, HAMMOND DW. Multiple liquid impacts on polymeric matrix composites reinforced with carbon nanotubes. Wear 2012;294-295:336-46. doi:10.1016/j.wear.2012.07.007. 61. HUANG J, RODRIGUE D. The effect of carbon nanotube orientation and content on the mechanical properties of polypropylene based composites. Mater Des 2014;55:653-63. doi:10.1016/j.matdes. 2013.10.039.

62. WANG L, ZHANG L, TIAN M. Effect of expanded graphite (EG) dispersion on the mechanical and tribological properties of nitrile rubber/EG composites. Wear 2012;276-277:85-93. doi:10.1016/ j.wear.2011.12.009

63. CAI D, JIN J, YUSOH K, RAFIQ R, SONG M. HIGH performance polyurethane/functionalized graphene nanocomposites with improved mechanical and thermal properties. Compos Sci Technol 2012;72:702-7. doi:10.1016/j.compscitech.2012.01.020.

64. LIU Y, WANG X, PAN G, LUO J. A comparative study between graphene oxide and diamond nanoparticles as water-based lubricating additives. Sci China Technol Sci 2013;56:152-7. doi:10.1007/s11431012-5026-Z.

65.TAI Z, CHEN Y, AN Y, YAN X, XUE Q. Tribological behavior of UHMWPE reinforced with graphene oxide nanosheets. Tribol Lett 2012;46:55-63. doi:10.1007/s11249-012-9919-6.

66. SHOKRIEH MM, HOSSEINKHANI MR, NAIMI-JAMAL MR, TOURANI $H$. Nanoindentation and nanoscratch investigations on graphene-based nanocomposites. Polym Test 2013;32:45-51. doi:10.1016/ j. polymertesting.2012.09.001.

67. FAN H, WANG L, ZHAO K, LI N, SHI Z, GE Z, et al. Fabrication, mechanical properties, and biocompatibility of graphene-reinforced chitosan composites. Biomacromolecules 2010;11:2345-51. doi:10.1021/bm100470q.

68. REN G, ZHANG Z, SONG Y, LI X, YAN J, WANG Y, et al. Effect of MWCNTs-GO hybrids on tribological performance of hybrid PTFE/ Nomex fabric/phenolic composite. Compos Sci Technol 2017;146:15560. doi:10.1016/j.compscitech.2017.04.022.

$\overline{\text { Manuscript received: } 14.11 .2017}$ 